\title{
Sex Difference in Human Mevalonate Metabolism
}

\author{
Kenneth R. Feingold, Millie Hughes Wiley, Gilbert L. Searle, \\ BRIAN K. MACHIDA, and MARVIN D. SIPERSTEIN, Cardiovascular Research Institute \\ and Department of Medicine, University of California, San Francisco and \\ Metabolism and Research Services of the Veterans Administration \\ Medical Center, San Francisco, California 94121
}

A B S T R A C T Two pathways of mevalonate metabolism have been demonstrated: the major (sterol) pathway leads to cholesterol synthesis, whereas the second shunts mevalonate away from sterol production and ultimately results in its oxidation to $\mathrm{CO}_{2}$. Previous studies have demonstrated that the female rat metabolizes circulating mevalonate by the shunt pathway at twice the rate of the male, whereas the male rat converts significantly more circulating mevalonate to cholesterol than the female. The present study extends these observations to humans. Six men and five premenopausal women with normal renal function were injected with $R, S-\left[5-{ }^{14} \mathrm{C}\right]$ mevalonate, and ${ }^{14} \mathrm{CO}_{2}$ expired in the breath of the subjects was monitored continuously with an ionization chamber. On an average, the female subjects expired $16.5 \%$ and the males $9.8 \%$ of the injected $R-\left[5-{ }^{14} \mathrm{C}\right]$ mevalonate $(P<0.001)$. No differences were observed in the plasma and erythrocyte $\left[{ }^{14} \mathrm{C}\right]$ cholesterol levels. These data demonstrate, in human beings, a sex difference in mevalonate metabolism. The overall impact of the greater mevalonate shunt activity on cholesterol balance in women is unknown.

\section{INTRODUCTION}

Mevalonic acid is an essential intermediate in the synthesis of both plant and animal sterols $(3,4)$. The further finding that the primary feedback control of cholesterogenesis is located at the site of mevalonate synthesis (5-8) has stimulated an intense interest in the metabolic fate of this cholesterol precursor. To date, two major metabolic pathways for circulating mevalonate have been documented in animals. The first; a

A portion of this research was presented at the Annual Meeting of the Western Society for Clinical Research, 7-9 February 1979 (1) and at the Annual Meeting of the American Society for Clinical Investigation 5-7 May 1979 (2).

Address reprint requests to Dr. Siperstein at the Veterans Administration Medical Center.

Received for publication 29 January 1979 and in revised form 17 March 1980. sterol pathway, leads to the synthesis of cholesterol $(9-12)$. The second, or nonsterol, pathway shunts mevalonate away from sterol production (13) and ultimately results in its oxidation to $\mathrm{CO}_{2}(14,15)$. In addition to these major pathways of mevalonate metabolism, quantitatively minor pathways leading to ubiquinone and dolichol have been described (16-18).

Previous in vivo and in vitro studies have demonstrated that the kidneys, rather than the liver, are the most active site of mevalonate metabolism by both the sterol $(12,15,19,20)$ and the nonsterol, or shunt pathways $(15,20-22)$. Studies in rats have further shown that there are major sex differences in circulating mevalonate metabolism by these two mechanisms (23). First, the female rat metabolizes circulating mevalonate by the shunt pathway at twice the rate of the male, a difference accounted for almost entirely by the greater ability of the female kidney to convert mevalonate to $\mathrm{CO}_{2}$. Second, the male rat converts significantly more circulating mevalonate to cholesterol than does the female. These findings are of particular interest because they represent the first evidence of a sex difference in cholesterol metabolism in any animal species. The present report extends these observations to humans and reveals that women metabolize circulating mevalonate by the shunt pathway to a significantly greater extent than do men.

\section{METHODS}

Subjects. Six men and five women participated in the study. The subjects were Caucasians betweeen the ages of 24 and $40 \mathrm{yr}$; they were in good health and taking no medications. None had a personal or family history of diabetes mellitus, renal disease, liver disease, or hyperlipidemia. Urinalysis and fasting glucose, urea nitrogen, and creatinine levels were normal in all subjects; pregnancy tests, carried out in the female subjects the day before the study, were negative. Informed consent was obtained from all subjects.

Study protocol. At 9:00 a.m., after an overnight fast, the subject was injected, via the antecubital vein, with $33 \mu \mathrm{Ci}$ of $R, S-\left[5-{ }^{14} \mathrm{C}\right]$ sodium mevalonate $(15 \mu \mathrm{Ci} / \mu \mathrm{mol})$ in $2 \mathrm{ml}$ of sterile, pyrogen-free, bacteriostatic saline. The expired breath of each subject was collected as described below and continuously 
monitored for $\mathrm{CO}_{2}$ concentration and radioactivity. For these procedures, an on-stream analyzer complex consisting of a flow meter, an ionization chamber with vibrating reed electrometer, and an infrared $\mathrm{CO}_{2}$ analyzer were used. Blood samples were obtained from the contralateral antecubital vein at 5-, 20-, 60-, 180-, and 540-min intervals during the study and at 1-, 2-, and 3-wk intervals after its conclusion. Total urine output was collected for $48 \mathrm{~h}$. The subjects were allowed to eat 3-4 $\mathrm{h}$ after beginning the study. At several additional intervals throughout the study, air collection was discontinued for 15 min. Five men and four women were studied over 9 -h periods, and the remaining man and woman were studied for $17 \mathrm{~h}$.

$\mathrm{CO}_{2}$ collection. During the study the subject wore a plexiglass helmet, tightly sealed at the shoulders. A flow system provided air at 7 liters/min from a compressed air tank. The expired air entered an ionization chamber, where the ${ }^{14} \mathrm{CO}_{2}$ was assayed with a Cary vibrating-reed electrometer (Varian Associates, Inc., Palo Alto, Calif.). The air then passed into an infrared carbon dioxide analyzer (Mine Safety Appliances Co., Pittsburgh, $\mathrm{Pa}$.), which produced an electrical signal proportional to the percentage of $\mathrm{CO}_{2}$ in the expired air. From the $\mathrm{CO}_{2}$ analyzer the air passed through a flow meter (Hastings, Hampton, Va.) and was exhausted outdoors. The ionization chamber was calibrated with known standards of ${ }^{14} \mathrm{CO}_{2}$. The infrared $\mathrm{CO}_{2}$ analyzer was calibrated with concentrations of $\mathrm{CO}_{2}$ varying between 0 and $3 \%$.

Nonsaponifiable lipids. The serum $(1 \mathrm{ml})$ and the erythrocytes $(1 \mathrm{ml})$ from each blood sample were placed in separate Erlenmeyer flasks and saponified by the addition of 5 $\mathrm{ml}$ of $90 \% \mathrm{KOH}: \mathrm{H}_{2} \mathrm{O}: 70 \% \mathrm{EtOH}(1: 2: 5)$ solution. The mixture was refluxed overnight on a warming plate. After the mixture had cooled, an internal standard of $\left[{ }^{3} \mathrm{H}\right]$ cholesterol was added and the nonsaponifiable material was extracted three times with petroleum ether. The petroleum ether extract was dried and taken up in $1 \mathrm{ml}$ of chloroform. A $0.1-\mathrm{ml}$ portion of the chloroform solution was dried in a scintillation counting vial. $10 \mathrm{ml}$ of scintillation counting solution $(1,000 \mathrm{ml}$ of toluene, $300 \mathrm{ml}$ of Beckman Bio-Sol III [Beckman Instruments, Inc., Fullerton, Calif.], $100 \mathrm{ml}$ of $\mathrm{H}_{2} \mathrm{O}$, and $6 \mathrm{~g}$ of 2,5-diphenyloxazole) was added to each vial. ${ }^{14} \mathrm{C}$ was assayed in a Beckman liquid scintillation counter (Beckman Instruments, Inc.) with the gain and discriminator window settings adjusted so that $<0.02 \%$ of the ${ }^{3} \mathrm{H}$ counts spilled into the ${ }^{14} \mathrm{C}$ window. The remainder of the chloroform solution was plated on a Sil G plate (Brinkmann Instruments, Inc., Westbury, N. Y.) and developed in ethyl acetate:benzene $(1: 5)$ for $60 \mathrm{~min}$. The areas on the plates that corresponded to standards of cholesterol, lanosterol, and squalene were placed in scintillation counting vials to which $10 \mathrm{ml}$ of scintillation counting solution was added. The ${ }^{14} \mathrm{C}$ was assayed at the window settings described.

Long-chain fatty acids. After the three basic extractions with petroleum ether to remove nonsaponifiable lipids, the water phase was acidified to $\mathrm{pH} 2$ with $\mathrm{HCl}$. The fatty acids were extracted with petroleum ether and then dried, and their ${ }^{14} \mathrm{C}$ content was assayed in the manner described for the nonsaponifiable lipids.

Urine studies. Urine samples were collected by four male and four female subjects for $0-6,6-12,12-24$, and $24-48 \mathrm{~h}$. The volume of urine was measured and $0.1 \mathrm{ml}$ of each urine collection was assayed for ${ }^{14} \mathrm{C}$ content in $10 \mathrm{ml}$ of the counting solution as described above. From the 0-6-h urine fraction, 10 $\mathrm{ml}$ of urine was acidified to $\mathrm{pH} 2$ with $\mathrm{HCl}$ and then extracted three times with ethyl ether. The ethyl ether extract was dried and taken up in $0.2 \mathrm{ml}$ of acetone which was plated on a Sil G plate. The plate was developed in ethyl acetate:benzene (1:1) for $30 \mathrm{~min}$ and then radioautographed (RP-14 x-ray film; Eastman Kodak Co., Rochester, N. Y.) for $3 \mathrm{~d}$.

Plasma lipid studies. Plasma cholesterol and triglyceride levels and lipoprotein cholesterol concentrations were determined by BioScience Laboratories (Van Nuys, Calif.).

Renal plasma flow. Renal plasma flow was determined using sodium iodohippurate ${ }^{131} \mathrm{I}$ by the method of Wagoner et al. (24). Sodium iodohippurate ${ }^{131} \mathbf{I}(100 \mu \mathrm{Ci})$ (E. R. Squibb \& Sons, Inc., Princeton, N. J.) was administered intravenously. After injection, 10-ml blood samples were obtained from the contralateral antecubital vein every $7 \mathrm{~min}$ for $70 \mathrm{~min}$. The serum was separated by centrifugation and the ${ }^{131} \mathrm{I}$ in $2-\mathrm{ml}$ aliquots of serum was determined with a Searle 1185 gamma counter (Searle Radiographics Inc., Des Plaines, Ill.). Renal plasma flow was calculated by plotting the ${ }^{131} \mathrm{I}$ counts vs. time on a semi-log scale. The disappearance curve was resolved into the sum of two exponential functions by curve subtraction. The $y$ intercept and the half-times of both lines were determined from the graph. Sodium iodohippurate clearance was calculated by the following formula:

$$
\mathrm{Cl}=\frac{0.693 \mathrm{I}}{\mathrm{AT}_{1 / 2 \mathrm{a}}+\mathrm{BT}_{1 / 2 \mathrm{~b}}},
$$

in which $I$ equals total injected radioactivity, $A$ and $B$ equal the intercepts, and $T_{1 / 2 \mathrm{a}}$ and $T_{1 / 2 \mathrm{~b}}$ represent the half-times of the respective lines.

\section{RESULTS}

The subjects' ages, heights, and weights are presented in Table I. The total plasma triglyceride and cholesterol levels and the cholesterol concentrations of the very low density lipoprotein (VLDL), ${ }^{1}$ low density lipoprotein (LDL), and high density lipoprotein (HDL) fractions were similar in both sexes and within the normal range (Table II). The amount and calculated percentages of injected $R-\left[{ }^{14} \mathrm{C}\right]$ mevalonate expired as ${ }^{14} \mathrm{CO}_{2}$ to infinity by each of the male and female subjects

${ }^{1}$ Abbreviations used in this paper: LDL, low density lipoprotein; HDL, high density lipoprotein; VLDL, very low density lipoprotein.

TABLE I

Description of Subjects

\begin{tabular}{ccccc}
\hline Subjects & Age & Weight & \multicolumn{2}{l}{ Height } \\
\hline & $y r$ & $l b$ & $f t$ & in. \\
Males & & & & \\
M.T. & 31 & 145 & 5 & 9 \\
F.C. & 34 & 142 & 5 & 8 \\
M.M. & 32 & 175 & 5 & 9 \\
G.M. & 24 & 155 & 5 & 8 \\
F.B. & 29 & 187 & 6 & 2 \\
R.W. & 34 & 200 & 6 & 0 \\
Females & & & & \\
M.B. & 27 & 125 & 5 & 7 \\
M.V. & 29 & 110 & 5 & 5 \\
A.V. & 31 & 150 & 5 & 7 \\
S.V. & 40 & 116 & 5 & 1 \\
G.B. & 29 & 145 & 5 & 9 \\
\hline
\end{tabular}


TABLE II

Lipoprotein Profiles

\begin{tabular}{lccccc}
\hline & & & \multicolumn{3}{c}{ Cholesterol } \\
\cline { 4 - 6 } & Cholesterol & Triglyceride & VLDL & LDL & HDL \\
\hline & & $m g / 100 m l$ & & & \\
Males & & & & & \\
M.T. & 146 & 13 & 1 & 97 & 46 \\
F.C. & 137 & 196 & 18 & 50 & 48 \\
M.M. & 190 & - & - & - & - \\
G.M. & 159 & 75 & 7 & 99 & 45 \\
F.B. & 152 & 47 & 4 & 94 & 49 \\
R.W. & 208 & 182 & 14 & 140 & 32 \\
Mean \pm SE & $165 \pm 11$ & $103 \pm 37$ & $8.8 \pm 32$ & $96 \pm 14$ & $44 \pm 3$ \\
Females & & & & & \\
M.B. & 211 & - & - & - & - \\
M.V. & 181 & 37 & 2 & 120 & 54 \\
A.V. & 158 & 57 & 8 & 108 & 39 \\
S.V. & 222 & 45 & 4 & 141 & 72 \\
G.B. & 155 & 35 & 7 & 94 & 54 \\
Mean \pm SE & $185 \pm 14$ & $44 \pm 5$ & $5.3 \pm 1.4$ & $116 \pm 10$ & $55 \pm 7$ \\
\hline
\end{tabular}

Differences between males and females are not significant $(P>0.10)$.

are given in Table III. Since ${ }^{14} \mathrm{CO}_{2}$ expiration after the first hour followed first-order kinetics, total ${ }^{14} \mathrm{CO}_{2}$ to infinity for each subject could be calculated readily from the values obtained for ${ }^{14} \mathrm{CO}_{2}$ expiration during the 9-h period according to the formula

$$
\mathrm{C}_{\infty}=\frac{\mathrm{C}_{\mathrm{t}}}{1-\mathrm{e}^{-\mathrm{kt}}},
$$

where $\mathrm{k}$ is the first-order rate constant. The female subjects expired a calculated average of $16.5 \%$ (range, $14.0-18.6 \%$ ) and the males $9.8 \%$ (range, $6.0-12.4 \%$ ) of the injected $R-\left[{ }^{14} \mathrm{C}\right]$ mevalonate. The difference in ${ }^{14} \mathrm{CO}_{2}$ production between the sexes was statistically

TABLE III

Conversion of $\mathrm{R}-\left[5-{ }^{14} \mathrm{C}\right]$ mevalonate to ${ }^{14} \mathrm{CO}_{2}$

\begin{tabular}{lccc}
\hline \multicolumn{4}{c}{$\begin{array}{c}\text { Percent injected R-[5-14C]mevalonate expired } \\
\text { as }{ }^{14} \mathrm{CO}_{2} \text { to infinity* }\end{array}$} \\
\hline \multicolumn{3}{c}{ Males } \\
& \multicolumn{3}{c}{ Females } \\
\hline M.T. & 8.6 & M.B. & 16.4 \\
F.C. & 10.0 & M.V. & 18.3 \\
M.M. & 12.1 & A.V. & 15.4 \\
G.M. & 12.4 & S.V. & 14.0 \\
F.B. & 9.7 & G.B. & 18.6 \\
R.W. & 6.0 & M.V.(2) & 16.1 \\
Mean \pm SE & $9.8 \pm 0.97$ & & $16.5 \pm 0.87$ \\
$P$ & & $<0.001$ & \\
\hline
\end{tabular}

* Calculated as described in text. significant $(P<0.001)$. During the $9 \mathrm{~h}$ of study, the males had expired an average of $70 \%$ (range, $64-73 \%$; $n=4$ ) and the females an average of $60 \%$ (range, $44-66 \% ; n=4$ ) of the calculated total ${ }^{14} \mathrm{CO}_{2}$ to infinity. These data indicate that the great majority of the metabolism of $\left[{ }^{14} \mathrm{C}\right]$ mevalonate to ${ }^{14} \mathrm{CO}_{2}$ occurred during the $9 \mathrm{~h}$ of study.

To confirm that first-order kinetics characterized the expiration of ${ }^{14} \mathrm{CO}_{2}$ from mevalonate over a more extended period of time, we studied one male and female subject for $17 \mathrm{~h}$. At the end of this period, ${ }^{14} \mathrm{CO}_{2}$ was no longer detectable in the expired air of either subject. The data in this study confirmed that first-order kinetics characterized the metabolism of $\left[{ }^{14} \mathrm{C}\right]$ mevalonate to ${ }^{14} \mathrm{CO}_{2}$ over at least a 17 -h period and furthermore, that the values calculated from $9-\mathrm{h}{ }^{14} \mathrm{CO}_{2}$ collections predicted values experimentally observed during the 17-h collection for the male and female subject studied: male calculated $17-\mathrm{h}$ value, $3.89 \times 10^{6}$ dpm; observed 17-h value, $3.69 \times 10^{6} \mathrm{dpm}$; female calculated 17 -h value, $4.39 \times 10^{6} \mathrm{dpm}$; observed $17-\mathrm{h}$ value, $4.50 \times 10^{6} \mathrm{dpm}$.

To determine the reproducibility of results, mevalonate metabolism in female subject M.V. was studied twice with an interval exceeding six months between experiments. The results observed ( 18.3 vs. $16.1 \%$ ) confirmed the reproducibility of the procedure in determining shunt pathway activity.

As noted earlier in rats, the majority of the oxidation of mevalonate to $\mathrm{CO}_{2}$ occurs in the kidney. All of our subjects had normal renal function as reflected by 
plasma blood urea nitrogen and creatinine. To evaluate renal function further, renal plasma flow was determined in several subjects. No significant sex difference in renal plasma flow was observed $(P>0.1)$ (Table IV); moreover, on regression analysis no significant correlation existed between individual shunt pathway activity and renal plasma flow $(r=-0.32)$.

Labeled cholesterol was found in the serum and erythrocytes of both the male and female subjects and attained maximum activity at $9 \mathrm{~h}$ in both sexes (Table V). The amounts of $\left[{ }^{14} \mathrm{C}\right]$ cholesterol per milliliter of serum or erythrocytes during the $3 \mathrm{wk}$ of observation were similar in the male and female subjects $(P>0.1)$. Labeled free fatty acids, lanosterol, and squalene were not detected in either the serum or erythrocytes of either the male or female subjects, perhaps because of the small amount of labeled mevalonate administered.

Table VI shows the percentage of injected $\left[{ }^{14} \mathrm{C}\right] \mathrm{meva}-$ lonate excreted in the urine in 6 and $48 \mathrm{~h}$. The majority of the ${ }^{14} \mathrm{C}$ was excreted during the first $6 \mathrm{~h}$. Female subjects excreted slightly more ${ }^{14} \mathrm{C}$ than males, but this difference was not statistically significant $(P>0.1)$. Thin-layer chromatography of ethyl ether-extracted urine revealed that the ${ }^{14} \mathrm{C}$ in the urine was present as a single spot, which migrated identically with $\left[{ }^{14} \mathrm{C}\right]-$ mevalonate. Presumably, the major portion of the ${ }^{14} \mathrm{C}$ present in the urine of both the male and female subjects represented unmetabolized $S$-mevalonate (10).

\section{DISCUSSION}

In 1974, Edmond and Popjak (13) first presented evidence that mevalonate is metabolized in the intact rat by a nonsterol, or shunt, pathway. The next year, Fogelman et al. (14) further demonstrated that this pathway is present in human males. Subsequent studies from our laboratory have shown that in the rat there is a marked sex difference in circulating mevalonate metabolism by the shunt pathway (23). In these in vivo studies, the female rat was found to metabolize more than $21.0 \%$ of circulating mevalonate to $\mathrm{CO}_{2}$ by this mechanism, whereas the male rat oxidized only $11.6 \%$ of mevalonate to $\mathrm{CO}_{2}$. The purpose

TABLE IV

Renal Plasma Flow

\begin{tabular}{crrr}
\hline \multicolumn{2}{c}{ Males } & \multicolumn{2}{c}{ Females } \\
\hline & & mllmin & \\
M.T. & 371 & G.B. & 324 \\
F.C. & 383 & S.V. & 229 \\
G.M. & 256 & A.V. & 310 \\
F.B. & 289 & & \\
Mean \pm SE & $325 \pm 31$ & & $288 \pm 30$ \\
$P$ & & $>0.1$ & \\
\hline
\end{tabular}

TABLE V

$\left[{ }^{14} \mathrm{C}\right]$ Cholesterol in Serum and Erythrocytes

\begin{tabular}{lrrrrr}
\hline & \multicolumn{2}{c}{ Male $(n=4)$} & & \multicolumn{2}{c}{ Female $(n=4)$} \\
\cline { 2 - 3 } \cline { 5 - 6 } Time & Serum & RBC & & Serum & RBC \\
\hline & \multicolumn{5}{c}{$d p m / m l$} \\
5 min & 10 & 9 & 5 & 10 \\
$20 \mathrm{~min}$ & 53 & 20 & & 40 & 29 \\
$60 \mathrm{~min}$ & 252 & 181 & & 286 & 153 \\
$3 \mathrm{~h}$ & 633 & 600 & & 615 & 703 \\
$9 \mathrm{~h}$ & 724 & 941 & & 726 & 1,119 \\
$1 \mathrm{wk}$ & 436 & 363 & & 532 & 479 \\
$2 \mathrm{wk}$ & 313 & 310 & & 310 & 297 \\
$3 \mathrm{wk}$ & 215 & 180 & 279 & 232 \\
\hline
\end{tabular}

Values are means for the four male and for the four female subjects. RBC, erythrocytes.

of the present study was to determine whether a comparable sex difference in mevalonate metabolism could be demonstrated in human beings.

The major finding of this investigation is that premenopausal women metabolize mevalonate to $\mathrm{CO}_{2}$ to a $68 \%$ (range, 43-90\%) greater extent than men of similar age. The women, on an average, expired $16.5 \%$ of the mevalonate as $\mathrm{CO}_{2}$, whereas the men oxidized an average of $9.8 \%$ of the mevalonate to carbon dioxide. Furthermore, that the sex difference in mevalonate metabolism by the shunt pathway persisted in this study when the ${ }^{14} \mathrm{CO}_{2}$ excretion was calculated to infinity supports the conclusion that the observed difference in mevalonate metabolism could not have been due to sex differences in the intravascular or intracellular pool sizes of mevalonate itself or of

TABLE VI

Urinary Excretion of ${ }^{14} \mathrm{C}$

\begin{tabular}{ccc}
\hline & $\begin{array}{c}\text { Percent injected } \\
{\left[{ }^{4} C\right] \text { Cevalonate }} \\
\text { excreted in } 6 \mathrm{~h}\end{array}$ & $\begin{array}{c}\text { Percent injected } \\
{\left[{ }^{4} \mathrm{C} C\right] \text { mevalonate }} \\
\text { excreted in } 48 \mathrm{~h}\end{array}$ \\
\hline Males & & \\
M.M. & 25.6 & 38.7 \\
F.C. & 47.5 & 58.0 \\
M.T. & 47.8 & 54.9 \\
G.M. & 46.9 & 52.9 \\
Mean \pm SE & $42.0 \pm 5.5$ & $51.1 \pm 4.3$ \\
Females & & \\
M.B. & 66.5 & 71.0 \\
M.V. & 54.8 & 61.5 \\
A.V. & 45.4 & 61.3 \\
S.V. & 45.1 & 52.9 \\
Mean \pm SE & $53.0 \pm 5.1$ & $61.9 \pm 3.9$ \\
\hline
\end{tabular}

Difference between male and female 6-h and 48-h excretion is not significant $(P>0.1)$. 
subsequent metabolites of mevalonate. Similarly, differences in renal function or renal blood flow cannot explain the observed sex difference in the oxidation of circulating mevalonate to $\mathrm{CO}_{2}$.

The concentration of plasma mevalonate in humans has recently been reported (25). The concentrations ranged from 20 to $>60 \mathrm{pmol} / \mathrm{ml}$ but in a majority of individuals ranged between 30 and $50 \mathrm{pmol} / \mathrm{ml}$. Unfortunately, from the published data it could not be determined if a sex difference in plasma mevalonate levels was present. Nevertheless, a difference in plasma mevalonate concentration would not be expected, as noted earlier, to alter the total quantity of ${ }^{14} \mathrm{CO}_{2}$ expired at infinity, but rather would only change the production rate of ${ }^{14} \mathrm{CO}_{2}$. Additionally, the amount of exogenous mevalonate administered was approximately 10 times greater than the entire circulating pool, which further reduces the possibility that differences in the circulating pool of mevalonate are the basis for the observed sex differences in metabolism.

Total plasma cholesterol levels and VLDL, LDL, and HDL cholesterol concentrations were normal in all our subjects. Within the limitation of the small number of subjects studied, shunt pathway activity did not correlate significantly with age, weight, cholesterol levels, triglyceride levels, or VLDL, LDL, and HDL cholesterol concentrations.

In our earlier study in rats, the female exhibited greater mevalonate shunt activity, whereas the male rat converted significantly more circulating mevalonate to cholesterol in the kidney than did the female. In this study of mevalonate metabolism in humans, we observed that the amounts of $\left[{ }^{14} \mathrm{C}\right]$ mevalonate incorporated into serum and erythrocyte cholesterol were similar in the two sexes. This finding does not, of course, rule out the possibility that there are sex differences in the human sterol pathway of mevalonate metabolism. A more definitive answer to this question requires the study of cholesterogenesis in tissues, such as kidney and liver, which represent the primary sites of cholesterol synthesis from circulating mevalonate $(12,15)$.

This study extends to human beings our earlier finding that the female uses the shunt pathway of mevalonate metabolism to a significantly greater extent than the male. This observation, moreover, represents the first evidence of a sex difference in humans in the metabolism of this cholesterol precursor. The overall impact of the greater mevalonate shunt activity on cholesterol balance in women is yet to be determined.

\section{ACKNOWLEDGMENTS}

This investigation was supported by the Medical Research Service of the Veterans Administration, by the Kroc Foundation, and by Program Project grant HL-06285 and grant CA15979 from the U. S. Public Health Service.

\section{REFERENCES}

1. Feingold, K. R., M. H. Wiley, G. Searle, and M. D. Siperstein. 1979. Sex differences in mevalonate metabolism in human beings. Clin. Res. 27: 85A. (Abstr.)

2. Feingold, K. R., M. H. Wiley, G. Searle, and M. D. Siperstein. Increased $\mathrm{CO}_{2}$ production from mevalonate in premenopausal females. Clin. Res. 27: 484A. (Abstr.)

3. Tavormina, P. A., M. H. Gibbs, and J. W. Huff. 1956. The utilization of $\beta$-hydroxy- $\beta$-methyl- $\delta$-valerolactone in cholesterol biosynthesis. J. Am. Chem. Soc. 78: 4498-4499.

4. Lynen, F., H. Eggerer, U. Henning, and I. Kessel. 1958. Farnesylpyrophosphat und 3-methyl- $\Delta^{3}$-butenyl-1-pyrophosphat, die biologischen vorstufen des squalens. Angew. Chem. Int. Ed. Engl. 70: 738-742.

5. Siperstein, M. D., and V. M. Fagan. 1966. Feedback control of mevalonate synthesis by dietary cholesterol. $J$. Biol. Chem. 241: 602-609.

6. Linn, T. C. 1967. The effect of cholesterol feeding and fasting upon $\beta$-hydroxy- $\beta$-methylglutaryl CoA reductase. J. Biol. Chem. 242: 990-993.

7. White, L. W., and H. Rudney. 1970. Regulation of 3hydroxy-3-methylglutarate and mevalonate biosynthesis by rat liver homogenates. Effects of fasting, cholesterol feeding, and triton administration. Biochemistry. 9: 2725-2731.

8. Rodwell, V. W., J. L. Nordstrom, and J. J. Mitschelen. 1976. Regulation of HMG CoA reductase. Adv. Lipid Res. 14: $1-74$.

9. Gould, R. G., and G. Popjak. 1957. Biosynthesis of cholesterol in vivo and in vitro from DL- $\beta$-hydroxy- $\beta$ methyl- $\delta-\left[2-{ }^{14} \mathrm{C}\right]-\mathrm{valerolactone}$. Proceedings of the Biochemical Society. 51. (Abstr.)

10. Goodman, D. S., J. Avigan, and D. Steinberg. 1963. Studies of cholesterol biosynthesis. V. The time course and pathway of the later stages of cholesterol biosynthesis in the livers of intact rats. J. Biol. Chem. 238: 1287-1293.

11. Garattini, S., P. Paoletti, and R. Paoletti. 1959. Lipid biosynthesis in vivo from acetate-1-C ${ }^{14}$ and $2-C^{14}$ and mevalonic-2-C $\mathrm{C}^{14}$ acid. Arch. Biochim. Biophys. 84: 253-255.

12. Hellstrom, K. H., M. D. Siperstein, L. A. Bricker, and L. J. Luby. 1973. Studies of the in vivo metabolism of mevalonic acid in the normal rat. J. Clin. Invest. 52: 1303-1313.

13. Edmond, J., and G. Popjak. 1974. Transfer of carbon atoms from mevalonate to $n$-fatty acids. J. Biol. Chem. 249: $66-71$.

14. Fogelman, A. M., J. Edmond, and G. Popjak. 1975. Metabolism of mevalonate in rats and man not leading to sterols. J. Biol. Chem. 250: 1771-1775.

15. Wiley, M. H., M. M. Howton, and M. D. Siperstein. 1977. The quantitative role of the kidneys in the in vivo metabolism of mevalonate. J. Biol. Chem. 252: 548-554.

16. Butterworth, P. H. W., H. H. Draper, F. W. Hemming, and R. A. Morton. 1966. In vivo incorporation of [2${ }^{14} \mathrm{C}$ ]mevalonate into dolichol of rabbit and pig liver. Arch. Biochem. Biophys. 113: 646-653.

17. Gough, D. P., and F. W. Hemming. 1970. The characterization and stereochemistry of biosynthesis of dolichols in rat liver. Biochem. J. 118: 163-166.

18. Gold, P. H., and R. E. Olson. 1966. Studies on coenzyme $Q_{9}$ in rat tissue slices. J. Biol. Chem. 241: 3507-3516.

19. Raskin, P., and M. D. Siperstein. 1974. Mevalonate metabolism by renal tissue in vitro. J. Lipid Res. 15: 20-25. 
20. Righetti, M., M. H. Wiley, P. A. Murrill, and M. D. Siperstein. 1976. The in vitro metabolism of mevalonate by sterol and non-sterol pathways. J. Biol. Chem. 251: 2716-2721.

21. Wiley, M. H., P. A. Murrill, M. M. Howton, S. L. Huling, D. C. Cohen, and M. D. Siperstein. 1977. The role of the kidneys in mevalonate metabolism: fact and artifact. Biochem. Biophys. Res. Commun. 79: 1023-1030.

22. Edmond, J., A. M. Fogelman, and G. Popjak. 1976. Mevalonate metabolism: role of kidneys. Science (Wash. D. C.). 193: 154-156.
23. Wiley, M. H., M. M. Howton, and M. D. Siperstein. 1979. Sex differences in sterol and nonsterol metabolism of mevalonate. J. Biol. Chem. 254: 837-842.

24. Wagoner, R. D., W. N. Tauxe, F. T. Maher, and J. C. Hunt. 1964. Measurement of effective renal plasma flow with sodium iodohippurate I 131. JAMA (J. Am. Med. Assoc.). 187: 811-813.

25. Popjak, G., G. Boehm, T. S. Parker, J. Edmond, P. A. Edwards, and A. M. Fogelman. 1979. Determination of mevalonate in blood plasma in man and rat. Mevalonate "tolerance" tests in man. J. Lipid Res. 20: 716-728. 